\title{
Using Better Management Thinking to Improve Conservation Effectiveness
}

\author{
Simon A. Black, ${ }^{1,2}$ Jim J. Groombridge, ${ }^{1}$ and Carl G. Jones ${ }^{3,4}$ \\ ${ }^{1}$ Durrell Institute of Conservation and Ecology, School of Anthropology and Conservation, \\ University of Kent, Canterbury, Kent CT2 7NZ, UK \\ ${ }^{2}$ Department of Human Resources, University of Kent, Canterbury, Kent, UK \\ ${ }^{3}$ Durrell Wildlife Conservation Trust, Trinity, Jersey, Channel Islands, UK \\ ${ }^{4}$ Mauritian Wildlife Foundation, Grannum Road, Vacoas, Mauritius
}

Correspondence should be addressed to Simon A. Black; s.black@kent.ac.uk

Received 29 April 2013; Accepted 30 May 2013

Academic Editors: A. Chistoserdov and D. Schmeller

Copyright (C) 2013 Simon A. Black et al. This is an open access article distributed under the Creative Commons Attribution License, which permits unrestricted use, distribution, and reproduction in any medium, provided the original work is properly cited.

\begin{abstract}
The current paradigm for effective management in biodiversity conservation programmes is dominated by three broad streams of thinking: (i) traditional "command-and-control" approaches which are commonly observed in, but are not exclusive to, bureaucratic government-administered conservation, (ii) more recent notions of "adaptive management," and (iii) emerging "good practice" management frameworks for conservation. Other variations on these themes suggested by the literature tend to endorse additions or enhancement to one or more of these approaches. We argue that instead a more fundamental alternative approach to conservation management is required, based on "systems thinking." The systems thinking approach should encompass (i) an understanding of natural systems, (ii) a sense of how human behaviour is influenced, (iii) an understanding of how knowledge should inform decision-making and problem solving, and (iv) an approach based on an understanding of variation in natural systems. Our argument is that the current paradigms of conservation management fail to address these four fundamentals and therefore do not represent the most effective way to manage conservation programmes. We suggest that the challenge for the conservation community is so great that conservation managers should seriously consider better ways of designing and managing programmes, setting goals, making decisions, and encouraging learning and improvement.
\end{abstract}

\section{Introduction}

A number of well-informed commentators have suggested that the dominant management mind-set observed in biodiversity management is one which follows a command-andcontrol philosophy [1-3]. Command-and-control management is characterised by top-down management hierarchies, functional specialism in teams, decisions made by managers rather than people doing the work, measurement by output (often against targets), and "management by results" (a focus on managing people and budgets) $[2,4-6]$.

A number of reviews of the conservation literature and the history of conservation successes and failures have identified common shortfalls of a "command-and-control" approach to conservation [1-3]. One reason for the continued widespread use of command-and-control management is that it is the common default mind-set observed in many different industrial, commercial, and public sectors [4-6], largely driven by underlying educational or governmental norms of thinking. This mind-set is therefore readily absorbed by managers, and those working in conservation are no exception $[2,4]$. A brief summary of the difficulties with commandand-control thinking includes the points raised by Holling and Meffe [1] who concluded that with this approach it is assumed that the problem is well bounded, clearly defined, relatively simple, and generally linear with respect to cause and effect, yet this set of assumptions does not fit well with the complex, nonlinear and poorly understood natural world. Furthermore, Holling and Meffe [1] issue a range of examples where command-and-control thinking is applied to natural systems and causes negative conservation outcomes, such as reducing genetic health in small populations, the damming of 
rivers, impacts from monoculture agricultural practices, and fire suppression in national parks, to name a few.

In the past two decades attempts to develop new management approaches in conservation have been offered. Adaptive management [7] is often portrayed as the most advanced approach to improving conservation outcomes [8,9]; indeed, the Convention on Biological Diversity specifically draws attention to adaptive management [10]. However, at the same time there is a common recognition that this approach is difficult to implement in practice [8]. There is also a suspicion that adaptive management processes and structures (such as decision-making processes and steering groups) are actually command-and-control practices in disguise, with all the inherent problems outlined above. This situation suggests a weakness in adaptive management practice; it appears dependent upon hierarchies where specialists remain in senior positions in committees rather than having a system of decision-making which embraces expertise on the ground [2]. This predicament means that knowledge is not placed in the correct position within governance structures (whether it is knowledge about techniques, sciences, budgets, or legal requirements), and policy and decisions are set that do not relate to the needs of the species, ecosystems, and environmental issues in question.

In this context, since the publication of the original adaptive management methodologies, the conservation community has witnessed several attempts to reframe the approach, including a suggestion of how "soft systems" methodologies could improve the conservation impact of adaptive management [8]. Despite these attempts, we argue that changes fail to question the core ideas around effective management and we suggest that a more fundamental "systems thinking" alternative is required, to set a new direction for effective conservation management.

Over the past decade, a third wave of management approaches has emerged in conservation in the shape of "good management practice" such as the IUCN framework for evaluating protected areas [11] and the Conservation Measures Partnership's open standards for the practice of conservation [12]. These frameworks offer an alternative approach, based on practice encountered in other sectors. However, the "standards" approach has been continually questioned $[4,13-15]$, for the constraints which this approach imposes on creativity and problem solving and for the bureaucracies that tend to follow the implementation of standards. In short, management standards should not be considered "good practice"; the standards may appear to work well on paper but are devoid of the flexibility that is commonly needed when managing conservation programmes. Conservation would be better served by management practices which can be implemented to the benefit of conservation work (see Table 1).

Conservation is a sector that lacks maturity in its experience of leadership and management thinking $[2,13,16]$; however the prevailing jumbled view of "good management practice" is not a peculiarly conservation-related phenomenon. Within management literature as a whole, the accumulated knowledge of what works and what does not is itself confused by "trends" and "fads" $[5,6,17]$. This confusion presents a problem since the temptation is to copy what appears to work (or at least what is purported to work) in more "managementsavvy" sectors. The result is that poor practice from external sectors (e.g., business, government, and public sector) is copied into the conservation community. Instead, we argue that any recommendations of "good management practice" need to (i) be founded on reliable theory, (ii) enable clarity of thinking in many and varied situations, (iii) offer clear ways in how they are applied in practice, and (iv) be applied such that continuous learning and improvement in conservation are achieved.

If a theoretical management base can be established which fits the demands of conservation science, social science, and organisational theory, then a foundation can be developed upon which to base effective conservation management. Deming [18], an outstanding management thinker of recent decades, asserts that "there is nothing as practical as a good theory."

\section{Methods for More Effective Management: Theory and Practice}

Good management practices need to be based on (i) foundations of reliable theory, (ii) thinking which can be applied in many and varied situations, (iii) approaches which can be clearly applied in practice, and (iv) continuous learning and improvement. We advocate that conservation managers focus on developing their capability across Deming's four areas of competence $[5,18]$.

2.1. Understanding of Conservation Systems in Terms of the Interplay between Natural Ecosystems and Human-Created Systems. At a fundamental level conservation programs are by their nature open systems [19]. This suggests that conservation managers need to understand their programmes and the interaction of all their elements, that is, the species, ecosystems, landscapes, human communities, work, teams, resources goals, budgets, and plans from a systems perspective [20]. Holling and Meffe [1] assert that "effective natural resource management that promotes long-term system viability must be based on an understanding of the key processes that structure and drive ecosystems and on acceptance of both the natural ranges of ecosystem variation and the constraints of that variation for long-term success and sustainability."

In terms of understanding human organisations as part of the system (i.e., the conservation programme itself and the teams involved) there is a critical need for managers to learn how things work $[3,13]$. Several indicators of effective management in relation to people and the organisation of work, decision-making, and problem solving are offered by Black et al., [2]: the setting of clear purpose and vision and having a clear consideration of both project details and the big picture. It is also possible for managers to map out their conservation programme to take account of approaches to organisation management (e.g., leadership, policy, resource management, and people) and natural systems management (e.g., species, ecosystems, and landscapes) and to identify areas for improvement; the Conservation Excellence Model 
TABLE 1: Contrasting approaches to management in a conservation context adapted from $[2,13]$.

\begin{tabular}{|c|c|c|c|c|}
\hline Principle & "Command-and-control" & Adaptive management & $\begin{array}{l}\text { "Good practice" } \\
\text { frameworks }\end{array}$ & Systems thinking \\
\hline Design perspective & Top-down hierarchy & $\begin{array}{l}\text { Top-down and } \\
\text { bottom-up }\end{array}$ & Top-down & $\begin{array}{l}\text { Open system, } \\
\text { outside-in }\end{array}$ \\
\hline Ethos & Control & Evidence-based & Compliance & Learning \\
\hline Design of work & $\begin{array}{l}\text { Specialist functions in } \\
\text { "silos" }\end{array}$ & $\begin{array}{l}\text { Functional specialism } \\
\text { with collaboration }\end{array}$ & $\begin{array}{l}\text { Follow elements of the } \\
\text { project plan }\end{array}$ & $\begin{array}{l}\text { Understand needs and } \\
\text { relevant flows of } \\
\text { activity }\end{array}$ \\
\hline Approach to change & Reactive projects & Trial and error & $\begin{array}{l}\text { Management as a } \\
\text { "process" using audit }\end{array}$ & $\begin{array}{l}\text { On-going, integral } \\
\text { (part of normal work) }\end{array}$ \\
\hline Motivation of people & $\begin{array}{l}\text { Extrinsic (reward and } \\
\text { reprimand) }\end{array}$ & Assumed consent & Compliance is required & $\begin{array}{l}\text { Intrinsic } \\
\text { (self-motivated) }\end{array}$ \\
\hline Decision making & $\begin{array}{l}\text { Separated from work } \\
\text { (carried out in the } \\
\text { hierarchy) }\end{array}$ & $\begin{array}{l}\text { Committees take } \\
\text { suggestions from } \\
\text { practitioners }\end{array}$ & $\begin{array}{l}\text { Made within the } \\
\text { boundaries of the } \\
\text { framework/project } \\
\text { plan }\end{array}$ & Integrated with work \\
\hline Measurement & $\begin{array}{l}\text { Output, targets, standards: } \\
\text { related to budget or plan }\end{array}$ & $\begin{array}{l}\text { Evidence-based } \\
\text { practices }\end{array}$ & Project sustainability & $\begin{array}{l}\text { Capability, statistical } \\
\text { data: link to purpose }\end{array}$ \\
\hline Attitude to stakeholders & Contractual & Participative & Inclusive & Cooperative \\
\hline Role of managers & $\begin{array}{l}\text { Manage people and } \\
\text { budgets }\end{array}$ & $\begin{array}{l}\text { Manage activities and } \\
\text { decisions }\end{array}$ & $\begin{array}{l}\text { Manage projects and } \\
\text { budgets }\end{array}$ & Act on the system \\
\hline Attitude to biodiversity & $\begin{array}{l}\text { Contractual: only do what } \\
\text { is required (e.g. only } \\
\text { follow the recovery plan) }\end{array}$ & $\begin{array}{l}\text { Consider impact of } \\
\text { actions on biodiversity }\end{array}$ & $\begin{array}{l}\text { Fit needs of } \\
\text { biodiversity within } \\
\text { project parameters }\end{array}$ & $\begin{array}{l}\text { Always start with "what } \\
\text { matters to } \\
\text { biodiversity?" (e.g. } \\
\text { species, habitats, etc.) }\end{array}$ \\
\hline
\end{tabular}

offers a framework to support this type of conceptual mapping [21].

Of course the work of conservation, be it species recovery, habitat restoration, policy implementation, law enforcement, socioeconomic restructuring, education, participatory management, or any other aspect, should become an intrinsic part of the system in which the programme is operating. In an ideal world the legacy of interventions will be left operating seamlessly within the natural systems once the conservation project teams have left. In practice, a hands-on element often remains as is most obviously the case with protected area management as well as numerous species recovery programmes. For example, 84\% of US Endangered Species Act species have been identified as currently conservation reliant, whilst other high profile examples from various continents including the Kakapo (Strigops 171 habroptilus), California Condor (Gymnogyps californianus), Black-footed Ferret (Mustela 172 nigripes), Florida Manatee (Trichechus manatus latirostris), the African Elephant (Loxodonta africana) and Gray Wolf (Canis lupus) are well-documented [3, 19, 22]. In addition there are an increasing number of programmes where wider ecosystem recovery is also managed [23]. Consequently, management is ever-present in many conservation programmes and hence should not be regarded as a oneoff concern but instead should be considered as a longterm influence with implications which will continue to run alongside the continued viability of the populations, species, and habitats.
Even in the most successful programmes, such as the recoveries of the California Condor and Black-footed Ferret, continued progress with species and ecosystems is reliant upon successful integration of human social systems such as hunting, land use, agricultural practice, or community attitudes towards the species $[2,22]$. Although we argue that a conservation managers' job is to understand species and ecosystems and to take action on causes of threat or decline [13], what this means in practice is that they need to learn how to establish measures of species and ecosystem status alongside measures of human impact, to identify priorities. "Systems thinking" enables better use of both natural and social scientific information for problem solving, decisionmaking, goal-setting, planning, and action [2]. It is a mindset change from what do we "think" is happening to what do we "know" is happening. However an understanding of systems is only one aspect of importance; it must be linked to the following three other areas of capability $[5,18]$.

\subsection{Using Information Properly, Whether Endowed with Either} Scientific Certainty, Imprecision, or Lack of Data. The first area of competence discussed above concerned how managers need to understand how a system operates. This needs to be linked to a second area of capability, an understanding of what "knowledge" really means [24]. Experience (i.e., what I have seen happen before or elsewhere) is subordinate to knowledge (what is happening now) [18]; opinion is different to facts [4], and problem solving, decisions, and work should 
be informed by knowledge $[5,6,18]$. Conservation has been cited as a "crisis discipline" [25], with a focus on problem solving and mitigation of threats. Knowledge should concern how conservation practitioners develop and regard data (e.g., population size, reproduction, mortality, and threats) and apply analyses (usually temporal and spatial) to guide work in response to circumstances and need.

The sciences of conservation often provide data-rich tapestries of information (genetics, population data, behavioural data, climate data, etc.) Conversely, rare and endangered species can be cryptic or in remote areas so many unknowns may also apply. Similarly, human systems (behaviour, resource use, and organisation) also have an impact on natural systems and vice versa [20], and these human aspects must also be understood. Human and social data may often be examined using social science techniques of which there is also a well-established body of knowledge within conservation.

Many conservation scientists commonly experience the need to handle imprecise data [26]. Hence, it is important that we make assumptions about the knowledge we gain by using a sound theory base [24]. In some areas knowledge will be precise, whilst in others it will be based on much less clear evidence or "belief" [24]. The competence needed by the conservation professional is when to seek precise data and when it is acceptable to rely on reasonable belief. For example, one area commonly accessed when making conservation decisions is social scientific data based on people's perceptions. In conservation projects it may be expedient to obtain perception data (from focus groups, interviews, and surveys) and this may be sensible, but the practitioner should also remain cautious since people's "points of view" (including those of conservation professionals) can be clouded by personal agendas. To put the practicalities of accommodating measurements of human behaviour in stark perspective, the theory of planned behaviour [27] identifies that people's views may not match their actual behaviour. In other words we should not assume knowledge of cause and effect based on perception data-people often say they will do one thing but actually do something else, or say one thing but actually believe something else. We should seek further (or alternative) data to inform our decisions.

Social data in the broadest sense can often be important; yet considerations of perception data specifically should not assume cause and effect linkages, but something more complex [20] which may give clues to how conservation can be improved. Useful analyses will give insights into which actions have an impact on the desired human behaviours. For example, if a community education programme fails to make a difference to people's behaviour towards a threatened species, we cannot assume that the programme is irrelevant nor can we assume that it is ineffective. It may simply have failed due to influences which are not being monitored which impact people's behaviour (e.g., demand for certain agricultural products, availability of alternatives to bush-meat, changes in political circumstances, war, road construction, etc.).

Conversely, there are occasions when attempting to acquire additional knowledge is counterproductive. The
Christmas Island Pipistrelle Bat (Pipistrellus murrayi) is an example where data monitoring continued in the face of population decline to the point of extinction [26]. The Po'ouli (Melamprosops phaeosoma), a recently extinct species of Hawaiian forest bird, was an example where plenty of data collection effort was applied but was not focused on what was needed to understand how to conserve the species until it was too late [28]. In these instances, reasonable assumptions could have been made (e.g., that the Poouli was very rare and in decline or that the Christmas Island Pipistrelle was declining to extinction), to enable early practical decisions about recovery effort to be made. Effort should have been focused in these instances on action to recover the species and subsequent accumulation of new knowledge about effective species recovery $[13,26]$.

It is not uncommon in conservation to encounter cases where data is deficient, yet the conservation community already has its own premise for these situations, the "Precautionary Principle" [29], which practitioners could benefit from keeping to the forefront of their minds. Spectacular recoveries have been demonstrated in species such as many of the endemic birds of Mauritius, including the Mauritius Kestrel (Falco punctatus), Pink Pigeon (Nesoenas mayeri), and Echo Parakeet (Psittacula eques) through application of reasonable belief of what is possible followed by progressive learning and action based on increased knowledge [22, 30].

\subsection{Understanding the Basics of Human Behaviour Rela-} tive to Their Work. Understanding systems and having a broad basis for building knowledge overcome two limitations of command-and-control thinking $[4,18]$. However the command-and-control paradigm also carries misplaced assumptions about people which also need to be overcome. One is an assumed cause and effect assumption between praise and motivation or sanctions and improvements in poor performance [4-6]. This assumption has been demonstrated not to be the case by numerous behavioural theorists and more recently by combinations of psychology and neuroscience [31]. Similarly, command-and-control assumes that organisations operate as the sum of their parts, so that goals, targets, and objectives can be set for individuals and teams on the assumption that the sum of those goals and targets will result in success, also a frequent misapprehension $[5,6$, $18,31]$. Knowing the performance of each element of your programme does not mean one is able to predict the outcomes of the whole [20].

Goal-setting is fraught with difficulty in terms of the psychological mind-set of workers [31]. The command-andcontrol assumption is that a target is set, which gives people understanding and clarity of purpose [5, 17]. However human responses to targets are far more complex. The most obvious examples of the failure to take account of this are in the goal displacement observed in the Black-footed Ferret programme and the Poouli $[2,13]$. In the early years of the Blackfooted Ferret programme, efforts to achieve goals relating to captive breeding of the animals were highly successful and became increasingly well resources, but parallel building of knowledge for their successful release and survival in the wild fell short, such that many animals were released 
into the wild, but few survived [3]. For the Poouli, goals set to fence protected areas to enable removal of invasive species diverted most programme resources, such that little was available to identify the needs of the bird itself [13]; the result was successful creation of protected, restored habitat, but loss of the endemic bird species for which it was intended. In these cases people were set goals which they followed in competition with peers and other departments involved in the programme $[3,13]$. In the end the overall purpose of the programme, to save the species, was fundamentally compromised.

The conservation practitioner therefore needs to develop an understanding of human psychology $[5,18]$. For example, human beings are motivated by having a sense of purpose and level of control over their work [31,32]. This is particularly important in conservation since many programmes involve people on the ground who have either high levels of technical or scientific knowledge or expert understanding of the species and landscapes under consideration (or both), plus high levels of passion and commitment to the work $[2,13]$. To deny them input and some level of control over decisionmaking, and work design is not only demotivating, it is organisationally an inefficient use of their human resource.

Furthermore, when thinking of the involvement of wider communities of people, the same basic understanding of human psychology applies. Community engagement should not simply be for involvement's sake [13] to "do the right thing," without properly understanding why those things should be done in the first place. Social inclusion should be for a particular purpose. For example, the practitioner needs to differentiate the process of social data collection from the usefulness of data. A "good" inclusive social process which engages local communities but gathers poor-quality or unhelpful data is, in the long term, of no value to the conservationist or the community. Similarly, data collected via a "poor" exclusive scientist-driven process which raises suspicion or anxiety in the local community and yet gathers high quality data may also be, in the long term, of little positive benefit. The practitioner should never be tied to method but should consider the psychological needs of the communities and other people who have an interest in the conservation outcome.

Recent [8] descriptions of "social learning" and "communities of practice," concerning a group, or groups, of people who share a concern for something that they do and learn how to do it better through regular interaction, appear helpful as a way to improve conservation effectiveness. From a systems perspective, social learning provides a model for testing and sharing methods and fitting practices into a local socioeconomic or ecosystem context. An example of this combination of social processes and data gathering is the routine collection of skull and tissue samples by hunting communities in the Peruvian Amazon [33], which are analysed by scientists and utilised by communities and conservationists to agree and manage sustainable off-takes.

Clearly, conservationists cannot escape the need to communicate with interested parties to gain relevant socioeconomic and political insights to inform interventions. However, stakeholder interaction may not necessarily assist conservation processes. For example, where extreme and opposing viewpoints occur (e.g., consulting animal rights activists about eradicating invasive mammals), involvement will likely hinder rather than help. Alternatively, decision makers may deliberately consult others to avoid making difficult and unpopular decisions themselves. Training people on how to engage with social groups may itself become a short-term fix.

Although there are calls to train conservation practitioners in methods or skill sets that will enable community involvement [8], we assert that it is far better to train them to understand how human beings function [5], what drives and predicts their behaviour, or at least which strategies to employ if the behaviours of workers or community partners do not fit expected patterns.

2.4. View Management through the Prism of Variation in Natural Systems. The final key area of learning which needs to be examined is how to base problem solving and management of interventions on an understanding of variation in natural systems. This principle was invoked by Deming [18] based on work of practitioners such as Shewhart [34]. Holling and Meffe [1] go as far as suggesting a "Golden Rule" in natural resource management: "natural resource management should strive to retain critical types and ranges of natural variation in ecosystems. That is, management should facilitate existing processes and variabilities rather than changing or controlling them." Making static comparisons of data on species or populations leaves many gaps in knowledge. It is not surprising that the most successful species recovery programmes are those which have been run over the long term, based on a growing knowledge of what works (and what does not) to improve the situation for the species $[3,13,22$, 35].

The majority of conservation practitioners have an appreciation for the need for data. The most progressive amongst them understand how to use that data to inform them on how well their interventions are progressing and what might need to change [2]. This understanding needs to be adapted to take account of longitudinal patterns of distribution, based on an understanding of variation in the natural systems which they study and work on. More challenging, however, is to apply the same thinking to human systems and organisation. Holling and Meffe [1] assert that one of the 6 ways to address the golden rule is to "examine bureaucracies to identify underlying reasons for their general intransigence and brittleness and promote incentives for alternative behaviours. Develop incentives and rewards for innovation that place streamlining, local solutions, and concern for sustainability above adherence to a command structure." This means that conservation managers should identify and manage those "system conditions" [4] which help or hinder improvements in the system. Those conditions might be budgets, rules, targets, role design, management expectations, logistical constraints, policies, methods, information, people with other agendas, or any number of things which can limit or enhance the effectiveness of conservation work. Alternatively, the problem can be reframed and new ways of collaboration be developed. As an alternative management perspective and a better way 
of working [18], the systems thinking approach can enable conservation managers to see through the bureaucracies of command structures and focus on the needs of species and ecosystems [2].

\section{Results and Impacts of Systems Thinking: The Human Dimension}

As human beings, conservationists are attempting to influence the natural and social systems which they encounter for the good of threatened species and ecosystems. In Caughley's seminal paper [36] which challenged the two conservation paradigms of his time (small-population versus declining population paradigm), he calls for conservation practitioners to improve the effectiveness of their work by pursuing three things: first, to seek knowledge; second, to identify how to improve the system; and third, to implement action where needed [36]. We endorse his ideas based on our presentation of effective management thinking. We assert that a broad understanding of management based on our suggested four areas of competence delivers the following beneficial results against each of his three factors.

\subsection{Conservation Effort and Emphasis Based on Increasing} Knowledge. In the 1970s there was a strong belief among many that the California Condor was a relic doomed to extinction and should be allowed to disappear with dignity [2]. With knowledge that the species decline was due to lead poisoning from shot left in abandoned sport-hunting carcasses, N. Snyder and H. Snyder working with colleagues redefined the conservation goals for the species and ensured its recovery [37]. Based on more complete knowledge (rather than assumed beliefs) a new approach for the conservation of the species took shape.

Attempts to upgrade conservation interventions by enhancing one mode of thinking such as adaptive management through addition of other modes of thinking such as soft system methodologies [8] will fail. Adding soft systems onto an incompatible approach risks further entangling professionals in the work of "management" rather than the actual work of conservation. To put it more bluntly, a conservation manager will end up spending time managing plans, coordinating procedures, and running workshops rather than doing the work of conservation. Instead, the conservation community needs to find other ways of incorporating and managing human behaviour and values.

3.2. Clarity of Intervention: How to Improve the System. In the conservation context, when enough knowledge is available, then decisions must be enacted; "decisions must be made whilst there is opportunity to act" [35]. Successful conservation programmes have a good understanding of the species, habitats, landscapes, and the threats that they are experiencing $[2,3,34,37]$. Conservation practitioners need to examine data objectively and then ask themselves "what is happening?" The simplest "good" solution is not always the best [38]; understand the system first and then act accordingly $[18,36]$.
Snyder and colleagues made the first inroads into conserving the California Condor after the species had experienced decades of decline by thoroughly examining the impacts on the species and correctly identifying the impact of lead shot left in abandoned carcasses and gut piles that caused fatal lead poisoning $[2,37]$. Other examples are apparent elsewhere where improvements have been achieved by a change in management mind-set; the Black-footed Ferret and Florida Manatee are just two examples $[3,13,26]$.

\subsection{Implementing Conservation: Relevant Methods and Stake-} holder Involvement. Evidence-based conservation [39] may offer some insights to assist in knowledge building practices by conservation practitioners. A strong systems thinking approach will help develop evidence-based approaches that can be used to refine conservation practice.

Relationships with stakeholders need to be managed so they have an appropriate role in managing conservation. Social data collection should be both inclusive and useful to communities and to the conservation scientist.

Whilst we recognise the importance of stakeholder interaction, the way in which conservation professionals use people's opinions should be seen as a distinct process. Conservationists often have to take difficult decisions and drive action which is contrary to some interests. Conservation programs need leaders who listen and take advice, but who are prepared to act based on evidence, rather than opinion. Thankfully, conservationists who worked with the California Condor did not concur with influential groups who advocated "extinction with dignity" [40], just as others [41] refused to abandon the Mauritius Kestrel to what some saw as an "all-but-inevitable fate" of extinction [42].

\section{Conclusion}

The failure to meet the Convention on Biological Diversity 2010 targets $[43,44]$ illustrates the need to fundamentally change conservation thinking. Conservation managers should, as Caughley [36] suggests, seek knowledge, identify how to improve the system, and implement action where needed. Continuous learning is particularly important for effective conservation, but it demands a sympathetic and proactive management culture. Useful recently suggested concepts of "evidence-based conservation" [39] offer better ways of encouraging conservation learning and a focus on practices which improve results; however methods should always be tested in the context of local knowledge of systems, variation, and people, so managers who use systems thinking will be best placed to use these ideas.

A breakthrough in performance is possible when conservationists manage conservation interventions taking account of natural systems of species and landscapes and impinging human systems (communities, agroforestry, politics, and business). In addition they must also be adept at working within their organisational structures and be able to manage the processes and people within the conservation programme. We suggest that four aspects of thinking should be aligned in the manager's approach; (i) how to understand 
the overall system being conserved (i.e., an interacting natural and human system); (ii) how to think about available knowledge, information, and data; (iii) how to take consideration of human psychology of people working in and around the programme; and (iv) how to understand variation when managing data in natural systems.

We encourage practitioners to develop a clear long-term vision; be "hands-on" in supporting the conservation team and understanding the work; be mindful of both detail and the big picture; and actively encourage a culture of learning, improvement, and receptiveness to alternative solutions.

\section{References}

[1] C. S. Holling and G. K. Meffe, "Command and control and the pathology of natural resource management," Conservation Biology, vol. 10, no. 2, pp. 328-337, 1996.

[2] S. A. Black, J. J. Groombridge, and C. G. Jones, "Leadership and conservation effectiveness: finding a better way to lead," Conservation Letters, vol. 4, no. 5, pp. 329-339, 2011.

[3] T. W. Clark, R. P. Reading, and A. L. Clarke, Endangered Species Recovery: Finding the Lessons, Improving the Process, Island Press, Washington, DC, USA, 1994.

[4] J. Seddon, Freedom from Command and Control, Vanguard Press, Buckingham, UK, 2003.

[5] P. R. Scholtes, "The new competencies of leadership," Total Quality Management, vol. 10, no. 4-5, pp. S704-S710, 1999.

[6] B. L. Joiner, S. Reynard, and A. Yukihiro, Fourth Generation Management: The New Business Consciousness, McGraw Hill, New York, NY, USA, 1994.

[7] C. S. Holling, Adaptive Environmental Assessment and Management, John Wiley \& Sons, Chichester, UK, 1978.

[8] G. Cundill, G. S. Cumming, D. Biggs, and C. Fabricius, "Soft systems thinking and social learning for adaptive management," Conservation Biology, vol. 26, no. 1, pp. 13-20, 2012.

[9] J. M. Dietz, R. Aviram, S. Bickford et al., "Defining leadership in conservation," Conservation Biology, vol. 18, no. 1, pp. 274-278, 2004.

[10] R. E. Kenward, M. J. Whittingham, S. Arampatzis et al., "Identifying governance strategies that effectively support ecosystem services, resource sustainability, and biodiversity," Proceedings of the National Academy of Sciences of the United States of America, vol. 108, no. 13, pp. 5308-5312, 2011.

[11] M. Hockings, S. Stolton, F. Leverington, N. Dudley, and J. Courrau, Evaluating Effectiveness: A Framework for Assessing Management Effectiveness of Protected Areas, International Union for Conservation of Nature, Gland, Switzerland, 2006.

[12] Conservation Measures Partnership, Open Standards for the Practice of Conservation (Version 2. 0), CMP, Washington, DC, USA, 2004.

[13] S. Black and J. Groombridge, "Use of a business excellence model to improve conservation programs," Conservation Biology, vol. 24, no. 6, pp. 1448-1458, 2010.

[14] P. Bansal and W. C. Bogner, "Deciding on ISO 14001: economics, institutions, and context," Long Range Planning, vol. 35, no. 3, pp. 269-290, 2002.

[15] J. A. Rodríguez-Escobar, J. Gonzalez-Benito, and A. R. Martínez-Lorente, "An analysis of the degree of small companies' dissatisfaction with ISO 9000 certification," Total Quality Management and Business Excellence, vol. 17, no. 4, pp. 507-521, 2006.
[16] J. C. Manolis, K. M. Chan, M. E. Finkelstein et al., "Leadership: a new frontier in conservation science," Conservation Biology, vol. 23, no. 4, pp. 879-886, 2009.

[17] J. Macdonald, Calling a Halt to Mindless Change, American Management Association International, New York, NY, USA, 1998.

[18] W. E. Deming, Out of the Crisis, Massachusetts Institute of Technology Center for Advanced Engineering Study, Cambridge, Mass, USA, 1982.

[19] R. L. Wallace, "The Florida Manatee recovery program: uncertain information, uncertain policy," in Endangered Species Recovery: Finding the Lessons, Improving the Process, T. W. Clark, R. P. Reading, and A. L. Clarke, Eds., pp. 131-156, Island Press, Washington, DC, USA, 1994.

[20] L. Bertalanffy, General System Theory: Foundations, Development, Applications, Revised edition, George Braziller, New York, NY, USA, 1969.

[21] S. A. Black, H. M. R. Meredith, and J. J. Groombridge, "Biodiversity conservation: applying new criteria to assess excellence," Total Quality Management and Business Excellence, vol. 22, no. 11, pp. 1165-1178, 2011.

[22] G. Caughley and A. Gunn, Conservation Biology in Theory and Practice, Blackwell Science, Cambridge, Mass, USA, 1996.

[23] D. D. Goble, J. A. Wiens, J. M. Scott, T. D. Male, and J. A. Hall, "Conservation-reliant species," BioScience, vol. 62, pp. 869-873, 2012.

[24] B. Russell, Theory of Knowledge, Encyclopaedia Britannica, Chicago, Ill, USA, 13th edition, 1926.

[25] M. E. Soulé, "What is conservation biology," BioScience, vol. 35, no. 11, pp. 727-734, 1985.

[26] T. G. Martin, S. Nally, A. A. Burbidge et al., "Acting fast helps avoid extinction," Conservation Letters, vol. 5, no. 4, pp. 274280, 2012.

[27] I. Ajzen, "The theory of planned behavior," Organizational Behavior and Human Decision Processes, vol. 50, no. 2, pp. 179211, 1991.

[28] J. J. Groombridge, J. G. Massey, J. C. Bruch et al., "An attempt to recover the Poouli by translocation and an appraisal of recovery strategy for bird species of extreme rarity," Biological Conservation, vol. 118, no. 3, pp. 365-375, 2004.

[29] K. R. Foster, P. Vecchia, and M. H. Repacholi, "Science and the precautionary principle," Science, vol. 288, no. 5468, pp. 979981, 2000.

[30] C. G. Jones, "Conservation management of endangered birds," in Bird Ecology and Conservation: A Handbook of Techniques, W. H. Sutherland, I. Newton, and R. E. Green, Eds., pp. 269-302, Oxford University Press, Oxford, UK, 2004.

[31] C. S. Jacobs, Management Rewired: Why Feedback Doesn't Work and other Surprising Lessons from the Latest Brain Science, Portfolio Books, New York, NY, USA, 2009.

[32] F. Herzberg, "One more time: how do you motivate employees?" Harvard Business Review, vol. 81, no. 1, pp. 87-141, 1976.

[33] J. L. Hurtado-Gonzales and R. E. Bodmer, "Assessing the sustainability of brocket deer hunting in the TamshiyacuTahuayo Communal Reserve, Northeastern Peru," Biological Conservation, vol. 116, no. 1, pp. 1-7, 2004.

[34] W. Shewhart, Economic Control of Quality of Manufactured Product, Van Nostrand, New York, NY, USA, 1931.

[35] T. Cade and W. Burnham, Return of the Peregrine: A North American Saga of Tenacity and Teamwork, The Peregrine Fund, Boise, Idaho, USA, 2003. 
[36] G. Caughley, "Directions in conservation biology," Journal of Animal Ecology, vol. 63, no. 2, pp. 215-244, 1994.

[37] N. Snyder and H. Snyder, The California Condor: A Saga of Natural History and Conservation, Academic Press, London, UK, 2000.

[38] P. Senge, The Fifth Discipline, Doubleday, New York, NY, USA, 1990.

[39] W. J. Sutherland, A. S. Pullin, P. M. Dolman, and T. M. Knight, "The need for evidence-based conservation," Trends in Ecology and Evolution, vol. 19, no. 6, pp. 305-308, 2004.

[40] D. Phillips and H. Nash, Condor Question: Captive or Forever Free? Friends of the Earth, San Francisco, Calif, USA, 1981.

[41] C. G. Jones, W. Heck, R. E. Lewis, Y. Mungroo, G. Slade, and T. Cade, "The restoration of the Mauritius kestrel Falco punctatus population," Ibis, vol. 137, supplement 1, pp. S173-S180, 1995.

[42] N. Myers, The Sinking Ark, Collins, London, UK, 1979.

[43] S. H. M. Butchart, M. Walpole, B. Collen et al., "Global biodiversity: indicators of recent declines," Science, vol. 328, no. 5982, pp. 1164-1168, 2010.

[44] Convention on Biological Diversity, Addis Ababa Principles and Guidelines for the Sustainable Use of Biodiversity, Secretariat of the Convention on Biological Diversity, Montreal, Canada, 2004. 

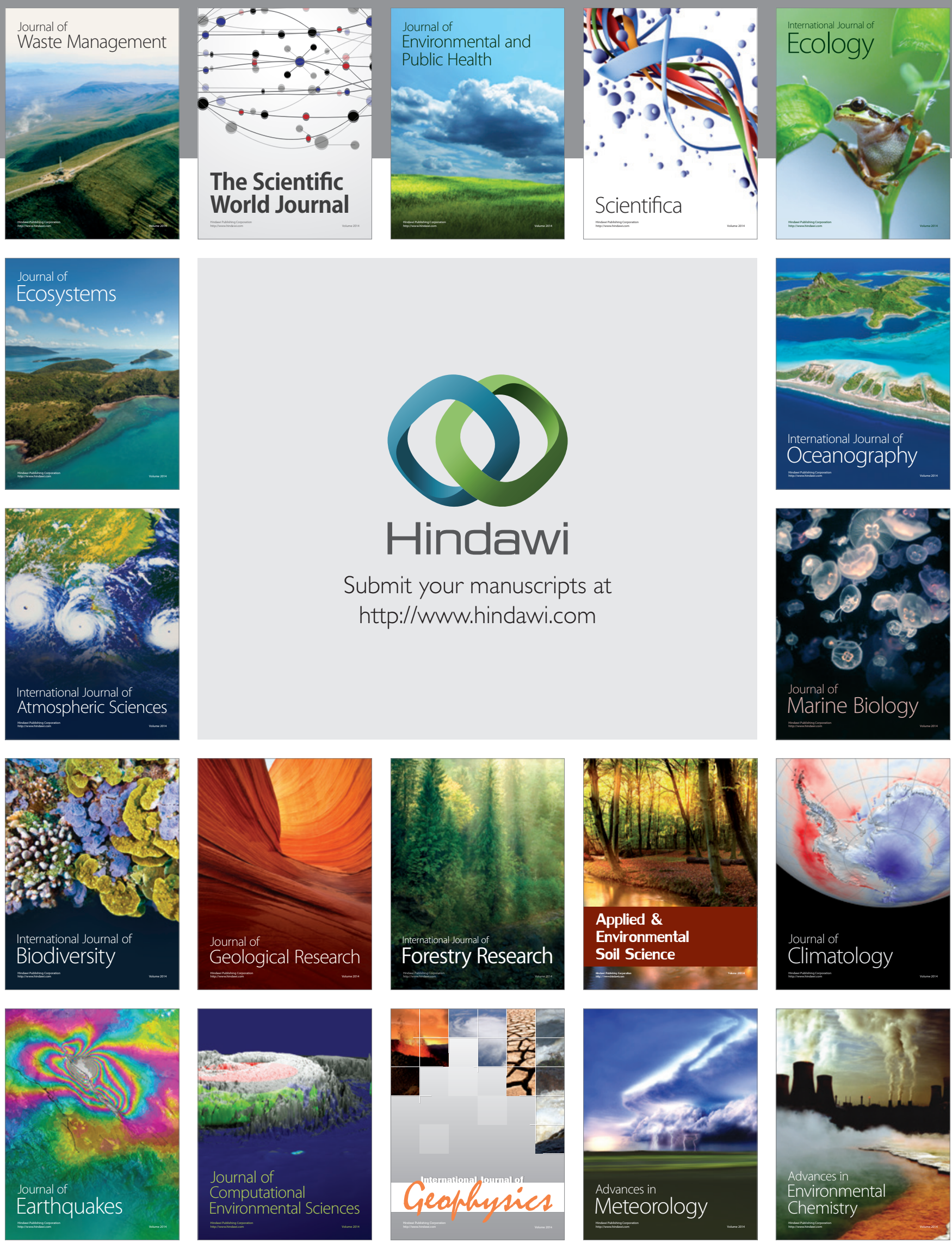